\title{
DESAIN KONVERTER BOOST DENGAN METODE KECERDASAN BUATAN BERBASIS MIKROKONTROLER STM32F103C8
}

\author{
Denny Irawan \\ Jurusan Teknik Elektro Universitas Muhammadiyah Gresik \\ E-mail : den2mas@umg.ac.id \\ JL. Sumatra No 101, Gresik 61121, Jawa Timur
}

\begin{abstract}
Energy conversion is needed to serve load characteristics according to consumer needs. Some of the human energy conversion techniques to date include: $A C$ to $D C$ (Rectifier), $A C$ to $A C$ (AC Controller), DC to AC (Inverter), DC to DC (Chopper).The use of electromechanical switching has begun to be reduced or even abandoned and replaced by electrical switching which has very high switching speeds.The energy conversion technique also includes the regulation of the output voltage produced by a converter so that current research is leading to the design of a reliable converter.Boost Converter is a converter that functions to regulate and increase the output voltage of the source voltage by setting its duty cycle.The optimal duty cycle value to produce the output voltage that is in accordance with the target, can be determined using the Flower Pollination (FPA) algorithm, together with the current sensor as feedback, and then controlled by the STM32F103C8 Microcontroller.
\end{abstract}

Keyword :Boost Converter, Flower Pollination Algorithm (FPA), STM32F103C8

\section{Latar belakang}

Saat ini hampir seluruh komponen elektronik memerlukan catu daya DC. Kebutuhan catu daya DC ini mulai dari skala tegangan rendah seperti yang digunakan pada mikroprosesor dan IC, tegangan menengah seperti pada motor-motor listrik dan generator, sampai pada skala tegangan tinggi untuk transmisi listrik tegangan tinggi. Karena penggunaan catu daya DC yang luas ini, diperlukan suatu sistem yang dapat mengkonversikan tegangan DC dari suatu tingkat tegangan tertentu ke tingkat tegangan lain sesuai kebutuhan pemakaian. Sistem ini harus dapat bekerja secara efisien dan keluaran tegangannya pun harus memiliki kualitas yang baik [1]. Perkembangan teknologi komponen dan rangkaian elektronika telah mampu menghasilkan sistem penyedia daya tegangan searah (DC), yang dihasilkan melalui konversi tegangan DC masukan ke bentuk tegangan DC keluaran yang lebih tinggi atau lebih rendah. Konversi tegangan DC ini biasa disebut sebagai konverter DC-DC.

Pada perkembangannya, dengan penerapan konverter DC-DC telah memungkinkan suatu perangkat elektronika dapat berfungsi dengan menggunakan sumber energi baterai yang berukuran kecil dimana tegangan keluarannya dapat diubah ubah sesuai kebutuhan pemakaian.

Hingga saat ini, berbagai konfigurasi konverter DC-DC telah banyak dikembangkan, diantaranya adalah jenis DC-DC konverter Boost. Konverter Boost merupakan salah satu Switching Regulator yang dapat menjawab kebutuhan akan kebutuhan tegangan yang berbeda - beda. 


\section{Dasar Teori}

\section{Konverter Boost}

Konverter Boost dikenal sebagai konverter DC yang mampu menghasilkan tegangan keluaran rata-rata $\mathrm{V}_{\mathrm{o}}$ yang lebih tinggi dibanding tegangan rata-rata sumber $V_{\mathrm{s}}$ [2]. Diagram rangkaian konverter Boost dengan menggunakan saklar power semikonduktor ditunjukkan pada gambar 1 .

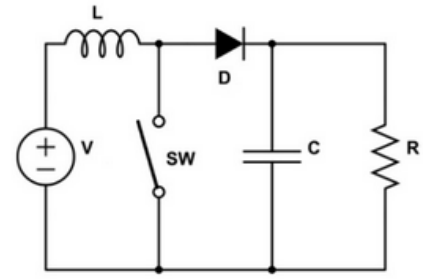

Gambar 1. Rangkaian konverter Boost

Cara kerja konverter Boost dijelaskan dalam 2 mode, mode 1 yaitu pada saat saklar konduksi, dalam hal ini pada $\mathrm{t}=0$ hingga $\mathrm{t}=\mathrm{t}_{1}$, arus akan mengalir dari sumber melalui induktor $\mathrm{L}$ dan beban R. Kondisi ini disebut pula periode pengisian arus induktor. Harga arus sesaat dimulai dari 0 , perlahan naik hingga maksimum.

Mode 2 diamati pada saat saklar Off, yaitu pada $\mathrm{t}=\mathrm{t}_{1}$ hingga saklar dinyalakan pada periode berikutnya. Pada mode 2, dioda freewheeling $\mathrm{D}$ akan konduksi karena adanya aliran arus pengosongan dari induktor. Karena arus yang mengalir adalah arus pengosongan induktor, dan induktor bersifat induktif murni (tidak ada nilai resistansi) maka arus akan membentuk kurva linier yang menurun.

Gambar 2 menunjukkan kurva arus yang mengalir melalui induktor L. Jika resistansi pada induktor adalah 0 (induktif murni), maka arus yang mengalir pada induktor akan naik secara linier dari 0 ke $\mathrm{I}_{\text {LMax }}$ pada waktu $\mathrm{t}=0$ selama periode DT. Demikian juga pada saat saklar Off, arus akan menurun linier selama periode (1-D)T.

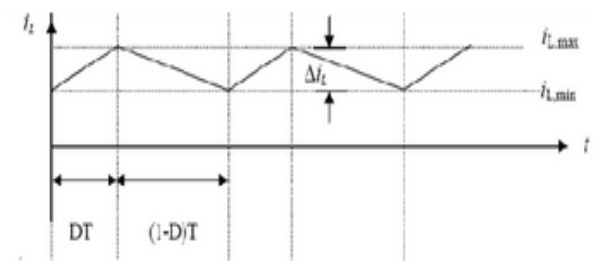

Gambar 2. Arus Induktor

Terdapat 2 kemungkinan mode arus yang mengalir yaitu :

- Mode arus kontinyu atau Continuous Current Mode (CCM)

- Mode arus diskontinyu atau Discontinuous Current Mode (DCM)

\section{Mikrokontroler STM32F103C8}

STM32 berbasis inti prosesor 32 bit RISC ARM Cortex-M7, Cortex-M4F, Cortex-M3, Cortex-M0+, dan CortexM0 dari STMicrelectronics.

Mikrokontroler ini mempunyai frekuensi clock tinggi, umumnya berada pada kisaran $72 \mathrm{MHz}$ atau lebih. ARM merupakan singkatan dari Advanced RISC Machine, sebuah prosesor 32-bit dengan tipe RISC. ARM Cortex ditujukan untuk aplikasi yang sifatnya embebbed seperti mikrokontroler, sistem kendali otomotif, printer serta sistem jaringan baik yang wired maupun wireles. Cortex-M digunakan pada mikrokontroler dengan kelebihan pada kecepatan kinerja dengan konsumsi daya yang rendah. Sedangkan Cortex-R dipakai pada aplikasi real-time [3].STM32F103C8 yang ditunjukkan pada Gambar 3, menggabungkan core RISC ARM®Cortex ${ }^{\circledR}-\mathrm{M} 3$ 32-bit berkinerja tinggi yang beroperasi pada frekuensi 72 $\mathrm{MHz}$, memori tertanam berkecepatan tinggi (memori Flash hingga 128 Kbytes dan SRAM hingga 20 Kbytes), dan berbagai pilihan I / Os yang disempurnakan dan periferal terhubung ke dua bus APB. Semua perangkat menawarkan dua ADC 12 bit, tiga timer 16 bit umum dan satu timer PWM, serta antarmuka komunikasi standar dan 
lanjutan: hingga dua I2C dan SPI, tiga USART, USB dan CAN [3]

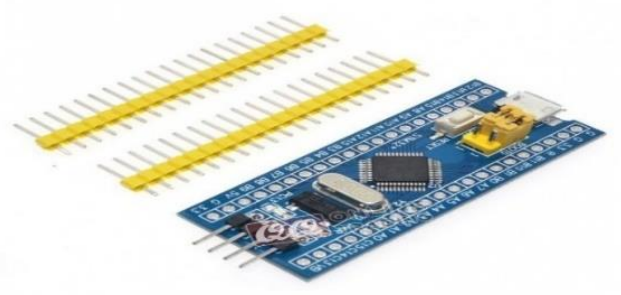

Gambar 3. Mikrokontroller STM32F103C8

\section{Modul Sensor Tegangan}

Prinsip kerja modul sensor tegangan yaitu didasarkan pada prinsip penekanan resistansi, dan dapat membuat tegangan input berkurang hingga 5 kali dari tegangan asli. Bentuk modul sensor tegangan seperti ditunjukkan pada gambar 4 berikut :

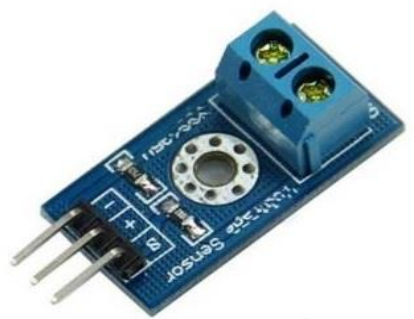

Gambar 4. Sensor Tegangan

\section{LCD}

LCD adalah lapisan dari campuran organik antara lapisan kaca bening dengan elektroda transparan indium oksida dalam bentuk tampilan sevensegment dan lapisan elektroda pada kaca belakang. Ketika elektroda diaktifkan dengan medan listrik (tegangan), molekul organik yang panjang dan silindris menyesuaikan diri dengan elektroda dari segmen. Lapisan sandwich memiliki polarizer cahaya vertikal depan dan polarizer cahaya horisontal belakang yang diikuti dengan lapisan reflektor. Cahaya yang dipantulkan tidak dapat melewati molekul-molekul yang telah menyesuaikan diri dan segmen yang diaktifkan terlihat menjadigelap dan membentuk karakter data yang ingin ditampilkan [5].

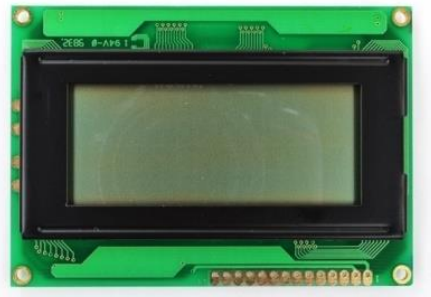

Gambar 5. LCD

\section{Flower Pollination Algorithm (FPA)}

Diperkirakan ada lebih dari seperempat juta jenis tanaman bunga di Alam dan bahwa sekitar $80 \%$ dari semua spesies tanaman adalah spesies bunga. Tujuan utama bunga pada akhirnya adalah reproduksi melalui penyerbukan. Penyerbukan bunga biasanya dikaitkan dengan pemindahan serbuk sari, dan pemindahan semacam itu sering dikaitkan dengan penyerbuk seperti serangga, burung, kelelawar, dan hewan lainnya. Bahkan, beberapa bunga dan serangga telah berevolusi bersama menjadi kemitraan penyerbuk bunga yang sangat khusus. Sebagai contoh, beberapa bunga hanya dapat menarik dan hanya dapat bergantung pada spesies serangga tertentu untuk penyerbukan yang berhasil [7].

\section{Perencanaan dan Pemodelan Konverter Boost}

Pada bagian ini akan dibahas mengenai perencanaan, pemodelan dan pembuatan alat. Diagram blok dari sistem secara keseluruhan adalah seperti ditunjukkan pada Gambar 6 berikut.

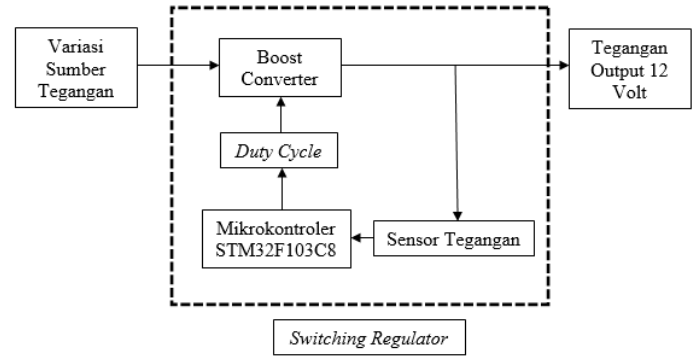

Gambar 6. Skema Rancangan Konverter Boost 
Dengan data komponen yang digunakansepertipadatabel 1 berikut :

Tabel 1. Parameter Perencanaan Konverter Boost

\begin{tabular}{|c|c|}
\hline Parameter & Nilai \\
\hline $\mathrm{V}_{\mathrm{s}}$ & $12 \mathrm{VDC}$ \\
\hline $\mathrm{S}$ & Saklar \\
\hline $\mathrm{D}$ & Dioda \\
\hline $\mathrm{L}$ & $0.53 \mathrm{H}$ \\
\hline $\mathrm{C}$ & $0.1 \mathrm{mF}$ \\
\hline $\mathrm{R}$ & $1 \mathrm{k} \Omega$ \\
\hline $\begin{array}{c}\text { Frekuensi } \\
\text { PWM }\end{array}$ & $10 \mathrm{kHz}$ \\
\hline Thyristor & IRF $540 \mathrm{~N}$ \\
\hline
\end{tabular}

Nilai parameter pada Tabel 1 dimodelkan pada Psim 9.3.4 sesuai gambar 7 .

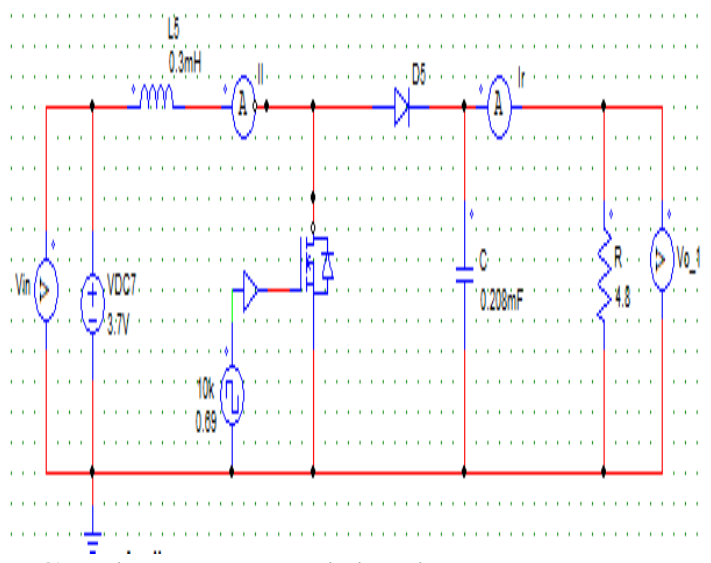

Gambar 7. Pemodelan konverter Boost

3. Pembuatan Alat Dan Analisa Hasil

Dari hasil pemodelan konverter Boost pada Psim 9.3.4 didapatkan hasil tegangan output sebagai berikut :
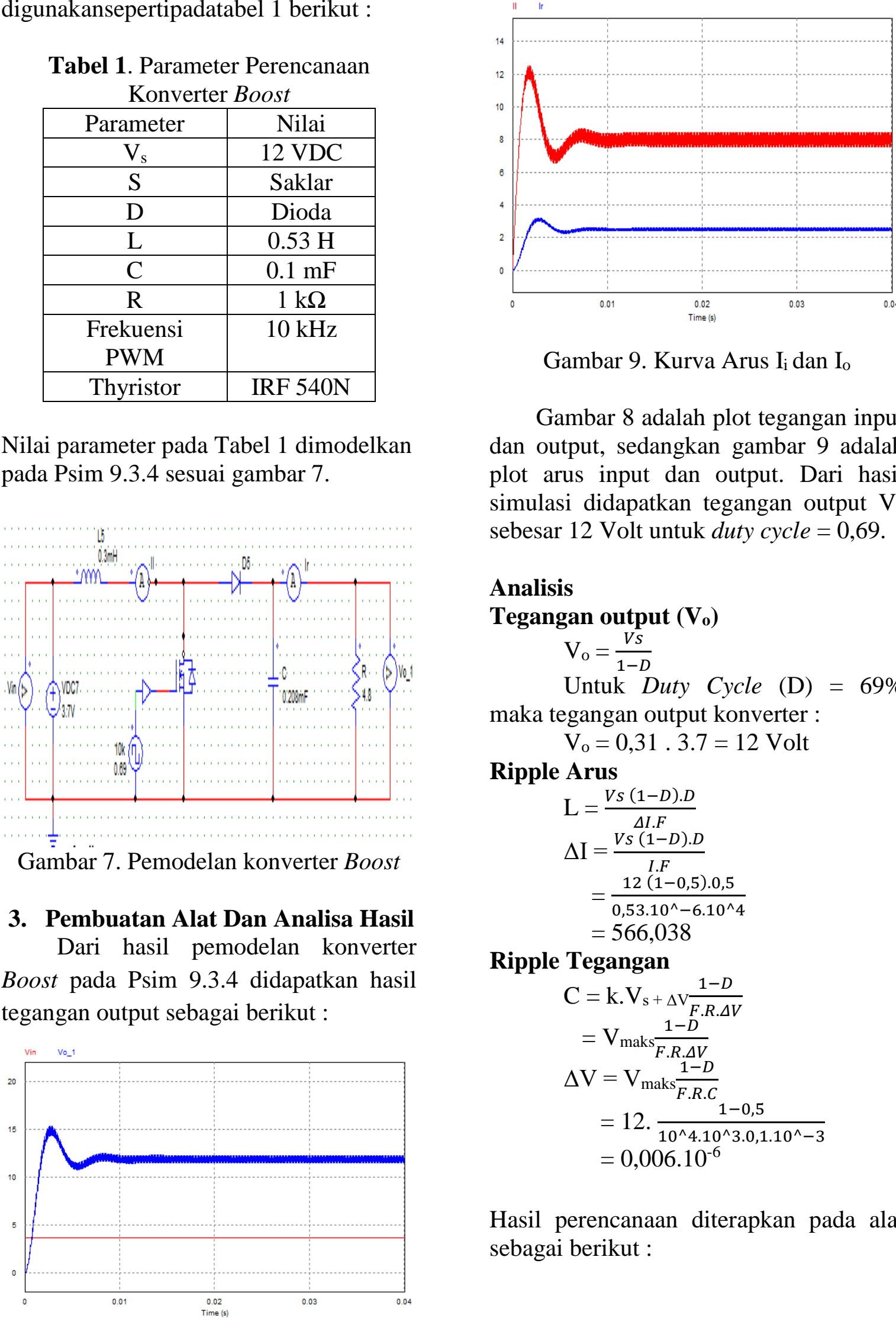

Gambar 9. Kurva Arus $\mathrm{I}_{\mathrm{i}}$ dan $\mathrm{I}_{\mathrm{o}}$

Gambar 8 adalah plot tegangan input dan output, sedangkan gambar 9 adalah plot arus input dan output. Dari hasil simulasi didapatkan tegangan output $\mathrm{V}_{\mathrm{o}}$ sebesar 12 Volt untuk duty cycle $=0,69$.

\section{Analisis}

Tegangan output $\left(V_{o}\right)$

$$
\begin{aligned}
& \mathrm{V}_{\mathrm{o}}=\frac{V s}{1-D} \\
& \text { Untuk Duty Cycle (D) }=69 \%
\end{aligned}
$$
maka tegangan output konverter :

$$
\mathrm{V}_{\mathrm{o}}=0,31 \cdot 3 \cdot 7=12 \text { Volt }
$$

\section{Ripple Arus}

$$
\begin{aligned}
\mathrm{L} & =\frac{V s(1-D) \cdot D}{\Delta I \cdot F} \\
\Delta \mathrm{I} & =\frac{V s(1-D) \cdot D}{I \cdot F} \\
& =\frac{12(1-0,5) \cdot 0,5}{0,53 \cdot 10^{\wedge}-6 \cdot 10^{\wedge} 4} \\
& =566,038
\end{aligned}
$$

\section{Ripple Tegangan}

$$
\begin{aligned}
\mathrm{C}= & \mathrm{k} \cdot \mathrm{V}_{\mathrm{s}}+\Delta \mathrm{V} \frac{1-D}{F \cdot R \cdot \Delta V} \\
= & \mathrm{V}_{\text {maks }} \frac{1-D}{F \cdot R \cdot \Delta V} \\
\Delta \mathrm{V} & =\mathrm{V}_{\text {maks }} \frac{1-D}{F \cdot R \cdot C} \\
& =12 \cdot \frac{1-0,5}{10^{\wedge} 4 \cdot 10^{\wedge} 3 \cdot 0,1 \cdot 10^{\wedge}-3} \\
& =0,006 \cdot 10^{-6}
\end{aligned}
$$

Hasil perencanaan diterapkan pada alat sebagai berikut :

Gambar 8. Kurva tegangan $V_{i}$ dan $V_{o}$ 


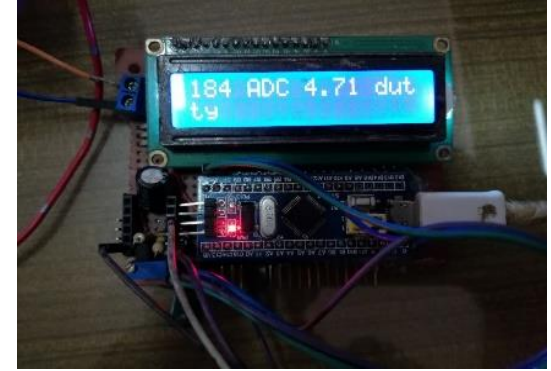

Gambar 10. Rangkaian PWM dan display

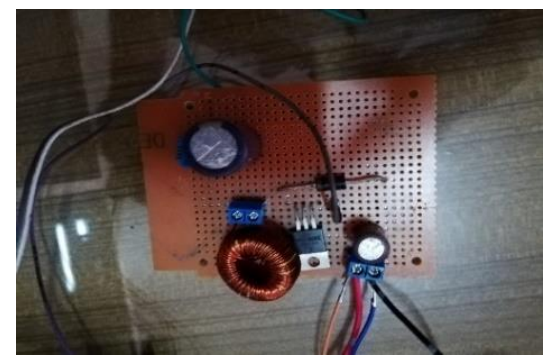

Gambar 11. Rangkaian konverter Boost

Gambar 10 adalah rangkaian Microcontroller STM32F103C8 sebagai penghasil sinyal PWM, lengkap dengan sensor tegangan, ADC dan LCD. Sedangkan gambar 11 adalah rangkaian konverter Boost sesuai hasil perencanaan. Hasil dari perencanaan konverter Boost sesuai pada tabel 2 dan 3 berikut :

\section{Pengujian konverter Boost}

Tabel 2 Pengujian konverter Boost

\begin{tabular}{|c|c|c|c|c|}
\hline No & duntty & $\begin{array}{l}\text { autput } \\
\text { (iv) }\end{array}$ & $\begin{array}{l}\text { input } \\
\text { (vi) }\end{array}$ & ingut (A) \\
\hline 1 & $5 \%$ & 192.6 & 17.9 & 0.02 \\
\hline 2 & $6 \%$ & 193.2 & 17.9 & 0.02 \\
\hline 3 & $7 \%$ & $\begin{array}{l}195.3 \\
\end{array}$ & 17.9 & 0.02 \\
\hline 4 & 83 & 196.5 & 17.9 & 0.03 \\
\hline 5 & $9 \%$ & 197.9 & 17.9 & 0.04 \\
\hline 6 & $10 \%$ & 199.2 & 17.9 & 0.05 \\
\hline 7 & $11 \%$ & 2000.7 & 17.9 & 0.05 \\
\hline 8 & $12 \%$ & 201.8 & 17.9 & 0.07 \\
\hline 9 & $13 \%$ & 203 & 17.9 & 0.08 \\
\hline 10 & $14 \%$ & 204.4 & 17.9 & 0.09 \\
\hline 11 & $15 \%$ & 206.9 & 17.9 & 0.11 \\
\hline 12 & $16 \%$ & 208.5 & 17.9 & 0.13 \\
\hline 13 & $17 \%$ & 209.4 & 17.9 & 0.14 \\
\hline 14 & $18 \%$ & 211 & 17.9 & 0.16 \\
\hline 15 & $19 \%$ & 212.7 & 17.9 & 0.18 \\
\hline 16 & $20 \%$ & 214.8 & 17.9 & 0.21 \\
\hline 17 & $21 \%$ & 216.7 & 17.9 & 0.23 \\
\hline 18 & $22 \%$ & 219.5 & 17.9 & 0.27 \\
\hline 19 & $23 \%$ & 221.3 & 17.9 & 0.79 \\
\hline 20 & $24 \%$ & 225.2 & 17.9 & 0.35 \\
\hline 21 & $25 \%$ & 229.1 & 17.9 & 0.41 \\
\hline 22 & $26 \%$ & 229.7 & 17.9 & 0.42 \\
\hline 23 & $27 \%$ & 233.3 & 17.9 & 0.48 \\
\hline 24 & 2835 & 235.8 & 17.9 & 0.53 \\
\hline 25 & $29 \%$ & 237.9 & 17.9 & 0.57 \\
\hline 26 & $30 \%$ & 242.7 & 17.9 & 0.68 \\
\hline 27 & $31 \%$ & 243.9 & 17.9 & 0.72 \\
\hline 28 & $32 \%$ & 252 & 17.9 & 0.85 \\
\hline 29 & $33 \%$ & 253.8 & 17.9 & 0.92 \\
\hline 30 & $34 \%$ & 256.7 & 17.9 & 103 \\
\hline 31 & $35 \%$ & 259.7 & 17.9 & 1.16 \\
\hline 32 & $36 \%$ & 265.1 & 17.9 & 13 \\
\hline 33 & $37 \%$ & 269 & 17.9 & 15 \\
\hline
\end{tabular}

\section{Pengujian Konverter Boost Dengan Algoritma FPA}

Tabel 2 Pengujian Konverter Boost Dengan Algoritma FPA

\begin{tabular}{|c|c|c|c|c|c|c|c|}
\hline \multicolumn{6}{|c|}{ Hasil pengkuran alat } & \multicolumn{2}{|c|}{ Hasil FFA } \\
\hline No & Input (V) & Input $(A)$ & Dutty cyde & output (V) & WP & dutty cycle & dutty eror \\
\hline 1 & 179 & 0.78 & 0.060 & 193.2 & 150.389206 & 0.0502 & 0.33 \\
\hline 2 & 17.9 & 0.77 & 0.070 & 1953 & 149.640212 & 0.0737 & 5.29 \\
\hline 3 & 17.9 & 0.76 & 0.080 & 1965 & 150 & 0.0799 & 0.13 \\
\hline 4 & 17.9 & 0.76 & 0.090 & 1979 & 149.574753 & 0.0881 & 2.11 \\
\hline 5 & 17.9 & 0.75 & 0.100 & 199.2 & 109.050559 & 0.0961 & 3.90 \\
\hline 6 & 17.9 & 0.74 & 0.110 & 200.7 & 148.65182 & 0.1061 & 3.55 \\
\hline 7 & 179 & 0.73 & 0.120 & 2018 & 147.934068 & 0.1192 & 0.67 \\
\hline 8 & 17.9 & 0.73 & 0.130 & 203 & 147.269089 & 0.1215 & 6.54 \\
\hline 9 & 17.9 & 0.72 & 0.140 & 204.4 & 146.72532 & 0.1311 & 6.36 \\
\hline 10 & 17.9 & 0.71 & 0.150 & 2069 & 145.940293 & 0.1434 & 4.40 \\
\hline 11 & 17.9 & 0.70 & 0.160 & 2085 & 145.480585 & 0.1477 & 7.69 \\
\hline 12 & 17.9 & 0.69 & 0.170 & 209.4 & 145.506756 & 0.1592 & 6.35 \\
\hline 13 & 17.9 & 0.69 & 0.180 & 211 & 144.996927 & 0.1709 & 5.06 \\
\hline 14 & 17.9 & 0.68 & 0.190 & 212.7 & 144.527182 & 0.1817 & 4.37 \\
\hline 15 & 17.9 & 0.67 & 0.200 & 214.8 & 144.296555 & 0.1859 & 7.05 \\
\hline 16 & 17.9 & 0.66 & 0.210 & 216.7 & 143.897553 & 0.1911 & 9.00 \\
\hline 17 & 179 & 0.66 & 0.220 & 219.5 & 144.05634 & 0.2119 & 3.68 \\
\hline 18 & 17.9 & 0.65 & 0.230 & 221.3 & 143.519751 & 0.2237 & 2.74 \\
\hline 19 & 17.9 & 0.64 & 0.240 & 225.2 & 144.297309 & 0.2399 & 0.04 \\
\hline 20 & 179 & 0.63 & 0.250 & 229.1 & 145.010606 & 0.2444 & 2.24 \\
\hline 21 & 17.9 & 0.63 & 0.260 & 229.7 & 143.596459 & 0.2596 & 0.15 \\
\hline 22 & 17.9 & 0.62 & 0.270 & 233.3 & 144.021277 & 0.2567 & 1.22 \\
\hline 23 & 17.9 & 0.51 & 0.280 & 235.8 & 143.715576 & 0.2781 & 0.68 \\
\hline 24 & 17.9 & 0.60 & 0.290 & 237.9 & 143.126239 & 0.2831 & 2.38 \\
\hline 25 & 17.9 & 0.59 & 0.300 & 242.7 & 144.103211 & 0.298 & 0.57 \\
\hline 25 & 17.9 & 0.59 & 0.310 & 243.9 & 142.891551 & 0.3084 & 0.52 \\
\hline 27 & 17.9 & 0.58 & 0.320 & 252 & 145.644931 & 0.3173 & 0.84 \\
\hline 28 & 17.9 & 0.57 & 0.330 & 253.8 & 144.674853 & 0.3237 & 1.91 \\
\hline 29 & 17.9 & 0.56 & 0.340 & 256.7 & 144.290451 & 0.3333 & 1.97 \\
\hline 30 & 17.9 & 0.55 & 0.350 & 259.7 & 143.911235 & 0.3495 & 0.14 \\
\hline 31 & 17.9 & 0.55 & 0.360 & 265.1 & 144.790861 & 0.3529 & 1.97 \\
\hline 32 & 17.9 & 0.54 & 0.370 & 269 & 144.772736 & 0.3593 & 2.89 \\
\hline & & & rata - rata er & & & & 3.03 \\
\hline
\end{tabular}

\section{Kesimpulan}

Berdasarkan hasil penelitian dan pengujian alat konverter Boost dengan metode Flower Pollination Algorithm (FPA), maka dapat disimpulkan sebagai berikut:

1. Sensor tegangan mempunyai toleransi kesalahan 2\% dari ring pengukuran $2.9 \mathrm{~V}$ sampai $30 \mathrm{~V}$, sumber pengukuran DC kurang murni tidak dianjurkan untuk bahan pengukuran, karena hasil dari DC kurang murni menyebabkan ketidak setabilan pengukuran.

2. Duty cycle PWM dengan algoritma FPA memberikan hasil yang lebih teliti.

\section{Ucapan Terima Kasih}

Ucapan terima kasih kepada semua pihak yang telah membantu dalam proses pembuatan dan penyusunan penelitian ini. Terutama Universitas Muhammadiyah Gresik yang telah memberi dana riset internal dosen 
yang diberikan kepada penulis dalam riset ini.

\section{Daftar Pustaka}

[1] Ashari, Mochammad., "Desain Konverter Elektronika Daya, INFORMATIKA Bandung,2017.

[2] Ashari, Mochammad., "Sistem Konverter DC, Desain Rangkaian Elektronika Daya, ITS Press,2012.

[3] Glover, B. J., Understanding Flowers and Flowering: An Integrated Approach, Oxford University Press, (2007).

[4] Muhammad H Rashid,"Power Electrinic Circuit Devices and Application",3rd Ed, Prentice Hall, 2004 [5] Pavlyukevich I., L'evy flights, nonlocal search and simulated annealing, J. Computational Physics, 226, 1830-1844 (2007).

[6] Yang, X. S., Engineering Optimization: An Introduction with Metaheuristic Applications, Wiley (2010) 